\title{
The First All-Russia Symposium on Surfactants "From Colloidal Systems to Nanochemistry" (with International Participation)
}

\author{
DOI: $10.1134 / \mathrm{S} 1061933 \mathrm{X} 11060093$
}

The First All-Russia Symposium on Surfactants (Cochairs Acads. A.I. Rusanov and A.I. Konovalov) was held on June 28-July 1, 2011, in Kazan at the Institute of Organic and Physical Chemistry, Kazan Scientific Center, Russian Academy of Sciences. The goal of the symposium was to discuss the theoretical and applied aspects of using surfactants in modern colloid chemistry, nanochemistry, and supramolecular chemistry. The symposium was implemented in accordance with the schedule of scientific measures within the framework of the International Year of Chemistry declared by the UNO Kazan Scientific Center, Russian Academy of Sciences; Academy of Sciences of the Republic of Tatarstan; Russian Foundation for Basic Research; Arbuzov Institute of Organic and Physical Chemistry, Kazan Scientific Center, Russian Academy of Sciences; and Mendeleev Russian Chemical Society and its Tatarstan Division, which were among the organizers of the symposium.

Scientists from 20 cities of Russia, Ukraine, and the United States, including Moscow, St. Petersburg, Kazan, Saratov, Tver, Volgograd, Nizhni Novgorod, Voronezh, Penza, Murmansk, Belgorod, Dzerzhinsk, Chernogolovka, Novomoskovsk, Shebekino, SergievPosad, Kyiv, Kharkov, Donetsk, Omakh, and others, took part in the symposium.

The scientific program of the symposium comprised 15 plenary lectures, 30 oral reports, and 83 posters devoted to the following fields:

- theoretical foundations of the physical and colloid chemistry of surfactants;

- surfactant-polymer systems: self-organization and functional properties;

- nanoreactors and nanocontainers based on amphiphilic compounds;

- surface phenomena, physicochemical mechanics, and adsorption processes involving surfactants;

-biological aspects of application of surfactants: biotechnology, enzymology, and pharmacy; and

-application of surfactants in oil-producing and refining industries.

An important place in the symposium procedure was occupied by lectures delivered by A.I. Rusanov, N.O. Mchedlov-Petrosyan, O.G. Us'yarov, and
A.K. Shchekin, which were devoted to the physicochemical aspects of association in surfactant solutions. Problems relevant to the creation of surfactant-based micellar nanoreactors for controlling cleavage of ester bonds and oxidation of hydrocarbons were considered in reports given by L.Ya. Zakharova, E.A. Kapricheva, O.T. Kasatkina, and R.F. Bakeeva. S.D. Varfolomeev discussed the modern achievements in the study of the functioning mechanisms of biological catalysts as biomacromolecules distinguished by structural organization. The prospects for using polymer micelles and surfactant (lipid)-water-oil systems as carriers of drugs were analyzed in reports presented by A.V. Kabanov and N.L. Klyachko. Modern trends in the development of chemical analysis in micellar nanoreactors were generalized by S.N. Shtykov.

The symposium held in Kazan showed that the physical chemistry of surfactants occupies one of the leading positions of the chemical sciences ensuring the technological progress. Reviews reported by M.Yu. Pletnev, I.S. Ryzhkina, Yu.F. Zuev, S.Yu. Zaitsev, R.Z. Syunyaev, et al., demonstrated that the spectrum of the practical applications of surfactants is extremely broad and covers strategic fields such as biotechnologies, medicine, ecology, catalysis, production of coatings, oil-producing, and oil-refining.

More than $60 \%$ of the participants of the symposium were represented by young scientists. The competition commission headed by Acads. A.I. Konovalov and A.I. Rusanov noted the high level of the lectures and posters delivered by postgraduate students and young researchers. The nine best communications, including oral reports presented by I.V. Kapitanov (Donetsk), I.M. Zorin (St. Petersburg), S.V. Kharlamov, A.N. Bezrukov, D.A. Kuryashov (Kazan), and Yu.S. Zubreva (Volgograd), were rewarded with diplomas and prizes.

The First All-Russia Symposium on Surfactants was a substantial step toward theoretical understanding and practical application of highly organized systems based on surfactants. It was proposed to repeat it and hold it every 2 years; the next one was decided to be held in Moscow in 2013.

L.Ya. Zakharova 